\title{
Migratory connectivity in Arctic geese: spring stopovers are the weak links in meeting targets for breeding
}

\author{
R. H. Drent · G. Eichhorn · A. Flagstad • \\ A. J. Van der Graaf $\cdot$ K. E. Litvin · J. Stahl
}

Received: 9 March 2007/Revised: 16 August 2007/Accepted: 17 August $2007 /$ Published online: 11 September 2007

(C) Dt. Ornithologen-Gesellschaft e.V. 2007

\begin{abstract}
Linking spring migratory itineraries of individual Arctic-breeding geese to their eventual breeding success has provided evidence that accumulation of body stores (protein, fat) at stop-over sites is crucial. We show that this is because geese nesting in the Arctic depend at least in part on these stores for synthesis of eggs and supporting incubation (for the female, a phase of starvation). Estimates of the body stores needed for successful reproduction (eggs + incubation) in relation to measured rates of accumulation of these stores make clear that meeting the demands solely by feeding at the breeding grounds is not an option for geese. The time constraint does not allow this, because early laying is a necessity in the Arctic to ensure survival of the progeny. Although the parents can exploit the early spring growth along the flyway, they get ahead of the wave of growth when they
\end{abstract}

Communicated by F. Bairlein.

R. H. Drent $(\bowtie)$ · G. Eichhorn · A. J. Van der Graaf

Animal Ecology Group,

Centre for Ecological and Evolutionary Studies,

University of Groningen, PO Box 14,

9750 AA Groningen, The Netherlands

e-mail: r.h.drent@rug.nl

\section{A. Flagstad}

Department of Small Animal Science,

Royal Veterinary and Agricultural University,

Dyrlaegevej 16, 1870 Frederiksberg, Denmark

\section{K. E. Litvin}

Bird Ringing Centre, Leninsky Prospekt 86-310,

Moscow 119313, Russia

J. Stahl

Landscape Ecology Group, University of Oldenburg,

26111 Oldenburg, Germany arrive on the breeding site and hence the parental timetable can only be met by drawing on body stores. Results from tracking studies in six goose species underline the conclusion that egg formation commences along the flyway before arrival at the nesting colony. In some cases, signatures of stable isotopes in egg components and parental body tissues in relation to the signature in forage plants support the notion of a mixed endogenous/exogenous origin. The close match between migratory timing and the spring flush of plant foods makes geese particularly vulnerable to the impact of climate change. There is an increasing mismatch along the NE Atlantic Flyway, where a warming trend in NW Europe conflicts with stable or even cooling trends in the Arctic target areas.

Keywords Capital breeding - Climate change . Energetic costs of incubation - Fat budgets .

Satellite tracking

\section{Introduction}

Migratory birds face the challenge of producing a clutch as soon as possible after arrival on the breeding grounds, since the prospects for progeny decline rapidly with advancing date (Sedinger and Raveling 1986; Sedinger and Flint 1991; Lepage et al. 1998; Prop et al. 2003; Bêty et al. 2003, 2004). Especially in demanding environments still in the grip of winter, the nesting female will face a shortage of foraging opportunities locally and may depend instead on nutrients garnered elsewhere along the flyway and sequestered in the body (notably stores of fat and protein) in order to meet her time schedule. Birds that follow this strategy of flying in materials for forming the eggs and supporting incubation have been termed 'capital breeders', 
as distinct from 'interest breeders' relying on nutrient sources collected locally on the breeding grounds following the rule 'pay as you go' (Drent and Daan 1980). Although these terms have been widely accepted, strict dichotomies are rarely valid in biology. Currently, the focus is on the quantification of the contributions from body stores on the one hand and nutrients garnered locally on the other, as we have come to realise that many (most?) bird species in fact follow a mixed strategy. In this paper, we return to Arctic-nesting geese that provided one of the classic examples of capital breeding (reviewed by: Meijer and Drent 1999; Klaassen 2003) and will consider new sources of information that clarify the situation. Figure 1 depicts the conventional terminology in distinguishing nutrient sources for avian reproduction. We consider the distinction between the use of 'endogenous' and 'exogenous' nutrient sources as equivalent to the 'capital' and 'interest' breeding strategies. Note that not only must we investigate the nutrient sources for hypertrophy of the reproductive tract and for synthesis of the eggs, but must also consider the balance sheet for incubation. In waterfowl, with very few exceptions, incubation is carried out solely by the female (Afton and Paulus 1992; Bowler 2005). Attentiveness is generally very high (usually above $90 \%$ of the $24 \mathrm{~h}$ ) and this preoccupation with the nest severely limits the time free for foraging. Collecting food is a time-consuming process in herbivorous species such as geese, so balancing the daily energy budget during incubation is potentially a problem for the female. Houston et al. (2007) have recently proposed a generalised model for female reproductive strategies, distinguishing capital from income breeding. Although formulated primarily for mammalian life histories, when applied to birds their model is not restricted to production of eggs alone, but includes transfer of maternal resources during incubation, conforming to our usage here.
Posing the question where migrant birds obtain the nutrients needed for reproduction ties in with the study of timing along the spring flyway. For waders and waterfowl returning to their Arctic breeding stations migration generally proceeds in relatively long leaps. Staging sites tend to be geographically confined and Alerstam et al. (1986) have pointed to the paradox that besides functioning as spring-boards, spring staging sites may potentially become bottle-necks whenever forage is in short supply. Alerstam and co-authors considered especially the role of competition, and in addition vagaries of the weather can lock up resources unexpectedly in ice and snow. Herbivorous migrants such as geese move up a climatological gradient, taking advantage of the spring flush of grass at each stopping place (Owen 1980). The growing grass has a higher digestibility and Drent et al. (1978) suggested that Barnacle Geese Branta leucopsis were riding the crests of digestibility waves as they moved during the course of the year, and termed it 'the Green Wave hypothesis'. For Arctic geese, the window of opportunity for laying eggs with good prospects is often as short as a single week in the year. This finding leads to the proposition that the geese at their destination are forced to get ahead of the green wave generated by spring growth in order to lay on time, underlining their reliance on capital breeding. Obviously climate change, especially if uneven along the flyway, is a threat to the reliability of this gradient in the spring growth the migrants depend on.

\section{Field approaches}

The classical approach to partitioning the nutrient sources used for breeding in geese has relied on (1) collecting specimens at intervals during the reproductive cycle and subsequently undertaking carcass analysis to follow
Fig. 1 Diagram elucidating distinction between use of endogenous versus exogenous nutrient sources for breeding in Arctic-nesting geese. Note that incubation is a phase of starvation

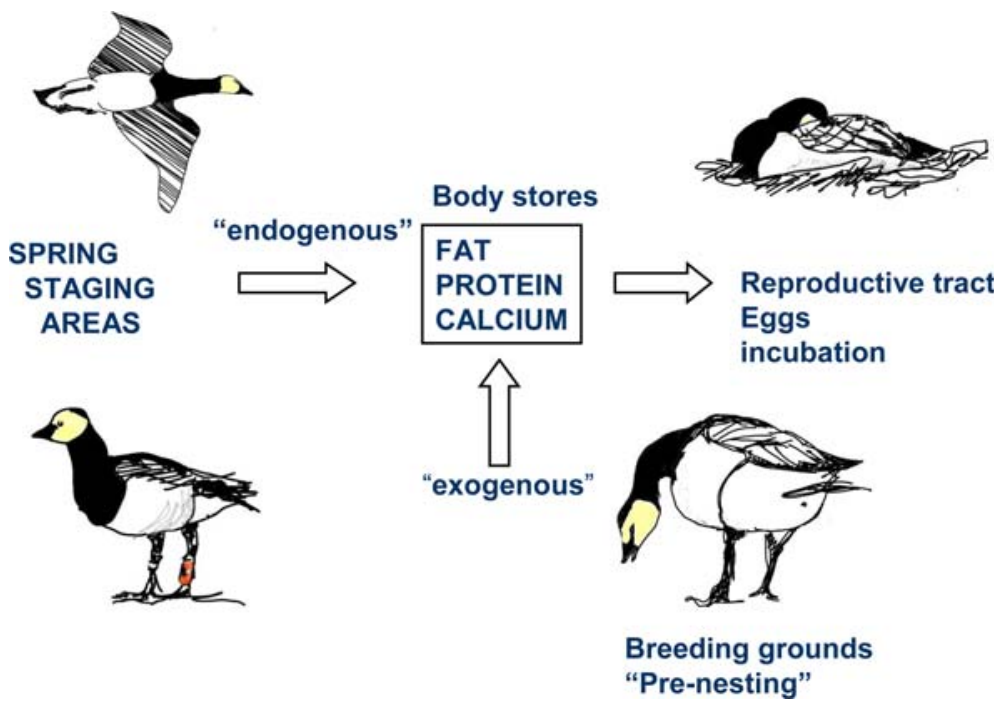


changes from arrival, through egg-laying to incubation. Quantifying these changes allows reconstruction of the allocation of body stores for breeding (reviewed by Alisauskas and Ankney 1992). The refinement of analysis techniques for stable isotopes has opened new avenues, as (2) the isotope signatures of egg components and body tissues reflect the signatures in the foods utilised for synthesis (reviewed in Hobson 2003, 2006). Especially where sharp switches in diet occur during migration (for example moving from marine to terrestrial foods as is typical for many waders and some geese), analysis of egg components and body tissues in relation to the candidate substrates can lead to clear-cut results (Klaassen et al. 2001; Schmutz et al. 2006). During the incubation phase, when the female is a prisoner on the nest, several indirect techniques have been employed to measure energetic costs. These include (3) periodic weighing of the sitting female using balances inserted beneath the nest (Spaans et al. 1999, 2007) and (4) repeated capture of the sitting female to ascertain total body stores of protein and fat by employing isotope enrichment (Groscolas et al. 1991; Speakman et al. 2001). This method relies on releasing isotopically labelled water molecules into the body and, after equilibration, determining isotope concentrations in the blood as a proxy for the body water. Since protein in the body is associated with a remarkably stable proportion of water, whereas fat is nearly free of water, the isotope values in conjunction with total body mass can be used to partition body stores into fat and protein compartments. In some species, it has been possible to measure gaseous exchange (5) by lowering a hood connected by pumps to analytical equipment over the sitting bird (Parker and Holm 1990; Gabrielsen et al. 1991). These measurements allow estimation of whole animal metabolism and can be compared to determinations on resting values from the same species collected by standard laboratory procedures. Finally (6), the doubly labelled water technique has sometimes been employed to measure total energy expenditure of incubating parents (Piersma et al. 2003) and is a method of great potential (capture and recapture is a prerequisite). The methods used in a number of goose studies are summarised in Table 1 .

These hands-on techniques can nowadays be supplemented by detailed information on the location of females in the period of egg formation. For most avian species, the period of explosive follicle enlargement when the egg is formed is known accurately, or can be closely approximated, and can be counted back from the observed laying date (Carey 1996). In special circumstances, direct observation of marked birds along the flyway can be related to laying dates of the same individuals (Prop et al. 2003). Tracking using miniature radios or satellite (PTT) transmitters has elucidated the whereabouts of individual geese with known laying dates during the critical pre-laying phase (Eichhorn 2005; Hupp et al. 2006b). The extensive comparative studies on Canada Geese Branta canadensis evaluated by Hupp et al. (2003, 2006a), as well as on Blue winged Teal Anas discors by Garrettson and Rohwer (1998) and Garrettson et al. (2000), clearly show that wherever possible abdominally implanted devices should be employed, as this technique has least adverse effects on behaviour, reproduction, survival and migratory timing.

\section{Results}

Energy requirement for incubation in waterfowl

Pooling data from a variety of waterfowl species justifies the simplification that the metabolic cost to the sitting female during steady (i.e. uninterrupted) incubation is closely related to resting metabolic rate (RMR). Daily energetic expenditure can thus reliably be predicted from body mass at least in the range above $1 \mathrm{~kg}$ (Fig. 2, methods and references indicated in key). To convert mass loss ( $\mathrm{g} /$ day) to energy ( $\mathrm{kJ} /$ day) we have employed the value of $24 \mathrm{~kJ} / \mathrm{g}$ body mass obtained by Le Maho et al. (1981) from experimental work on fasting geese (closely similar to conversion factors in four other non-passerines including the Common Eider Somateria mollissima; see Spaans et al. 2007; Boismenu et al. 1992). The most notable feature of this compilation is that all values lie below the predicted RMR according to the most recent predictive allometric body mass relationship for swans and geese of Miller and Eadie (2006). It should be pointed out, however, that using a multi-species relationship for predicting RMR for individuals with large fat stores in the body (such as our incubating females) is bound to lead to overestimation as fat is a metabolically inert tissue. In any case, energetic expenditure during quiet incubation is apparently kept to a minimum. Also shown is the contribution of body stores in covering these costs, and it will be noted that most of these uniparental incubators follow a mixed strategy supplementing foraging inputs during nest absences by drawing on body stores of fat and protein. Two species qualify as 'pure capital incubators': the Common Eider and the Greater White-fronted Goose Anser albifrons (Spaans et al. 1999; not shown in Fig. 2) which did not feed throughout. Now we face the question of the origin of these body stores supporting nearly a month of fasting. An approximation of the time course required for building up these fuel stores in the body can be derived from information on maximum fuel deposition rates in migrating birds.

Lindström (2003) compiled a massive data set on mean daily body mass increments from populations as well as individuals of migratory birds sampled in the field at intervals during episodes of rapid fuelling (48 populations 


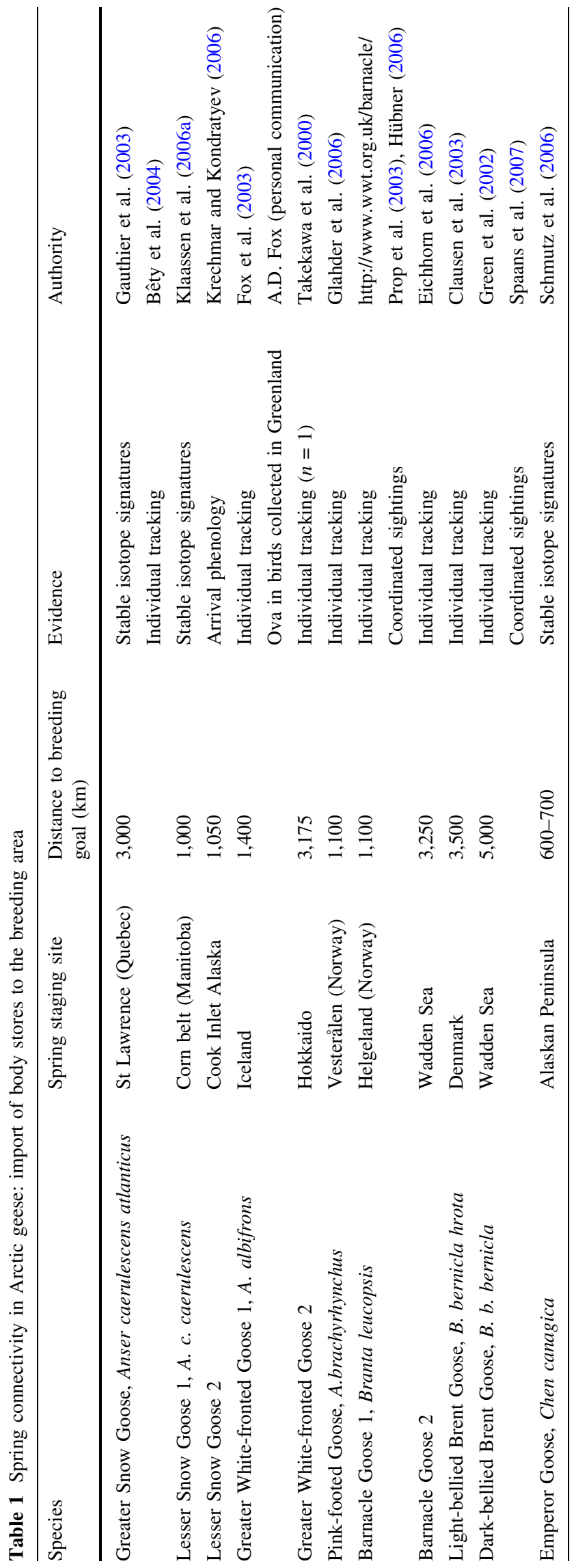

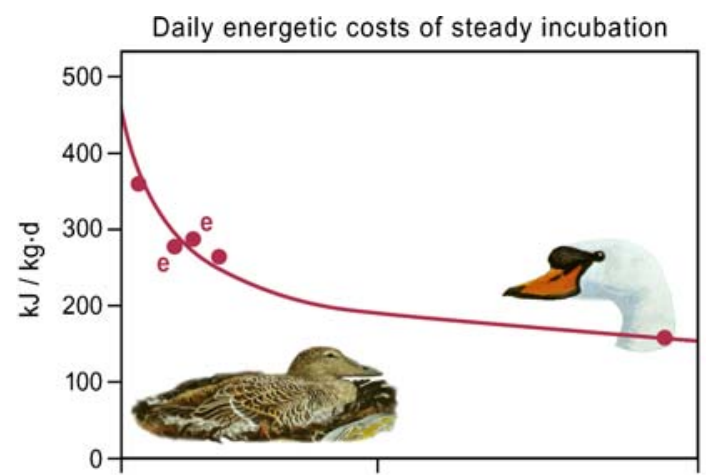

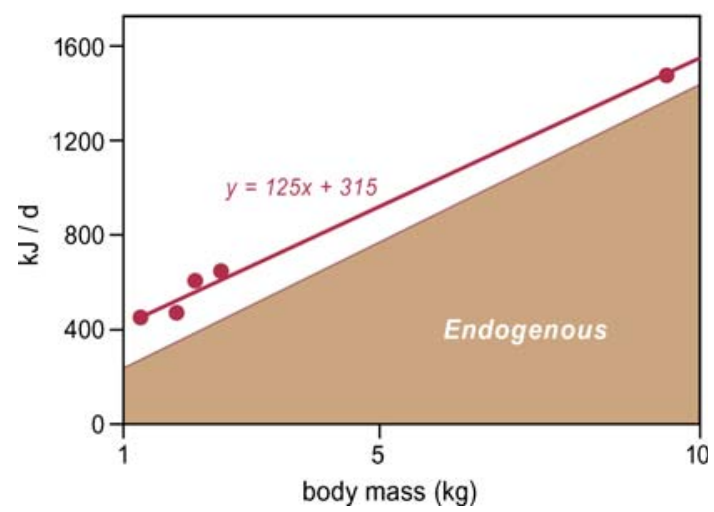

Fig. 2 Daily energetic costs during steady incubation in relation to lean body mass in waterfowl depicted as energetic intensity $(\mathrm{kJ} / \mathrm{kg} /$ day) upper panel and total costs ( $\mathrm{kJ} / \mathrm{day}$ ) below. The formula $y$ (in $\mathrm{kJ})=125 \times($ body mass in $\mathrm{g})$ estimates daily costs $\left(R^{2}=0.99\right)$. 1 = Branta bernicla bernicla (adapted from Spaans et al. 2007), 2 = Somateria mollissima (adapted from Parker and Holm 1990), 3 = Somateria mollissima (adapted from Gabrielsen et al. 1991), $4=$ Anser caerulescens (Ankney in Afton and Paulus 1992), 5 = Cygnus olor (adapted from Ubels et al., unpublished manuscript). The proportion of the daily requirement met from body stores is shown diagrammatically by the shaded area "endogenous"

and 39 individuals, respectively, covering 59 species in all). He found that maximum daily fuel deposition rates expressed as percentage increment in relation to lean body mass did not depend on avian group (passerine or nonpasserine), but depended strongly on body mass (BM, in $\mathrm{kg}$ ) according to the formula $1.16 \mathrm{BM}^{-0.35}$ (populations) and $2.17 \mathrm{BM}^{-0.34}$ (individuals). Relative daily fuel deposition rates thus decline with increasing body mass: heavier species require more time to achieve the same proportional increase. The waterfowl species in our dataset on incubation energetics (Fig. 2) are best represented in the 'population' set in Lindström (2003), and we will use that relationship in further calculations. Accepting the simplification that the mass increments measured in Lindström's dataset when migrants are 'fattening' is energetically similar $(\mathrm{kJ} / \mathrm{g})$ to the body stores drawn upon during incubation, we can carry out a first approximation of the time required (in days) to build the stores sequestered by the female before undertaking incubation. 
For the two goose species where contribution from the body stores during incubation has been estimated, empirical estimates are available on fuelling rates (Lindström 2003; and our own data). Females would require 1012 days to accumulate the stores consumed during incubation (assuming full allocation towards body reserves during fuelling, i.e. no competing needs such as egg formation). For the Common Eider, we have approximated the fuelling rate from Lindström's formula (13 g/day) and, on this basis, accumulating the body stores needed to support full incubation (24.2 days at $20 \mathrm{~g} /$ day; see Parker and Holm 1990; Gabrielsen et al. 1991) would require 38 days (again a minimal estimate assuming no competing requirements). To typify Arctic-breeding swans, calculations can be provided for Bewick's Swan Cygnus columbianus (LBM and incubation period from Reese 2006). Assuming that $90 \%$ of the energetic requirement (from the formula in Fig. 2) is withdrawn from the body, then accumulating the necessary body stores would take 35 days (daily fuelling rate from Lindström's 2003 formula works out at $0.7 \%$ at the LBM of $4.1 \mathrm{~kg}$ ). This exercise demonstrates the extended timespan female waterfowl need to accumulate the body stores essential to complete incubation successfully. Field observations confirm that females feed intensively before laying, but the requirements for synthesis of ovaries and eggs will compete with accumulation of body stores for later use. Energy deposition to pay for incubation will thus extend over more than the 10-38 days we have computed here. Precise information on arrival times in the breeding colonies can serve to put these minimal fuelling times in perspective, to help answer the question where fuelling for incubation occurs.

Arrival dates in relation to egg-laying

Precise intervals between arrival at the colony and laying of the first egg have been obtained in several goose species breeding in the Arctic. Hupp et al. (2006b) tracked individual Emperor Geese Chen canagica returning to the nesting colony on the Yukon-Kuskokwim Delta in Alaska. In two seasons with early snow melt, the median interval between arrival and first egg was 11 days (mean 10 days, $n=15$ ) and slightly longer in a season of late snow melt (median 15 days, $n=20$ ). In the early seasons, some individuals arrived only 4 days before laying, and Hupp et al. (2006b) conclude that in these years more than $50 \%$ of the geese likely initiated rapid follicle growth prior to migrating from the spring staging sites in the Alaskan Peninsula (600-700 km away). According to the tracking data the geese spent 30-40 days at these spring fuelling stations. The geese utilise marine foods at that time (especially the shellfish Macoma) and switch to terrestrial foods when they reach the breeding grounds. This dietary switch forms a convenient time marker for employing stable isotopes, since the signatures of the food types are readily distinguished. On this basis, Schmutz et al. (2006) were able to confirm that endogenous stores available to the Emperor Goose during incubation indeed derived from marine environments (presumably the intertidal habitats in the Alaskan Peninsula). According to isotope analysis, nutrients in the egg were a mix of terrestrial and intertidal sources, conforming to the time patterns of movements of the geese revealed by the tracking studies.

Eichhorn (2005) and Eichhorn et al. (2006) employed satellite tracking and Global Location System loggers in Barnacle Geese at a breeding colony in Arctic Russia, where laying dates of these individuals could be determined from direct observation, and found that the 12-day phase of rapid follicular development was spread over a number of localities along the Arctic coast within $700 \mathrm{~km}$ and hence only a few hours flying time of the nest site (Figs. 3 and 4). Most geese arrived in the colony 4-6 days before laying the first egg, but one individual laid the very day she arrived. These findings imply a mixed strategy of using endogenous and exogenous nutrient sources for egg formation and, in view of the time scale of building up the fat stores required to sustain incubation (see above), this mixed strategy applies equally to the incubation phase. Prop et al. (2003) studied spring migration in the Spitsbergen breeding population of the same species, relying on intensive observation of individually ringed birds. The interval between departure from the last 'spring-board' in northern Norway and settling in the colony on Spitsbergen (1,100 km away) averaged 19-20 days for 14 successful females (respectively in late and early seasons). During this interval, the geese obtain some food in snow-free patches on Spitsbergen, notably SW-facing mountain slopes where snowmelt is early. At one such site, intensive observation of ringed individuals indicated that one-fifth of the Spitsbergen population made at least a short stop at this prebreeding station where they gained considerable fat stores (Hübner 2006). Individual fat stores at the Norwegian staging site, as revealed by the abdominal profile index (for calibration of this technique see Madsen and Klaassen 2006), were a good predictor of breeding success in that season (Prop et al. 2003).

Although laying dates were not obtained for the Lightbellied Brent Branta bernicla hrota studied during spring migration by satellite telemetry (Clausen et al. 2003), these data again point to a role for 'import' of nutrients for breeding. One pair (each carrying a transmitter) migrated from Denmark (departure 30 May) to NE Greenland (arrival 2 June, final destination 4 June) and subsequently returned with at least one gosling. Stopover during this epic spring journey (c. 3,500 km) was extremely limited (48-59 h) and 
Fig. 3 Migratory flyway of the Russian population of the Barnacle Goose Branta leucopsis, determined from ring recoveries (1965-2003) and results from satellite tracking (autumn 2004, spring 2005; adapted from Eichhorn 2005)

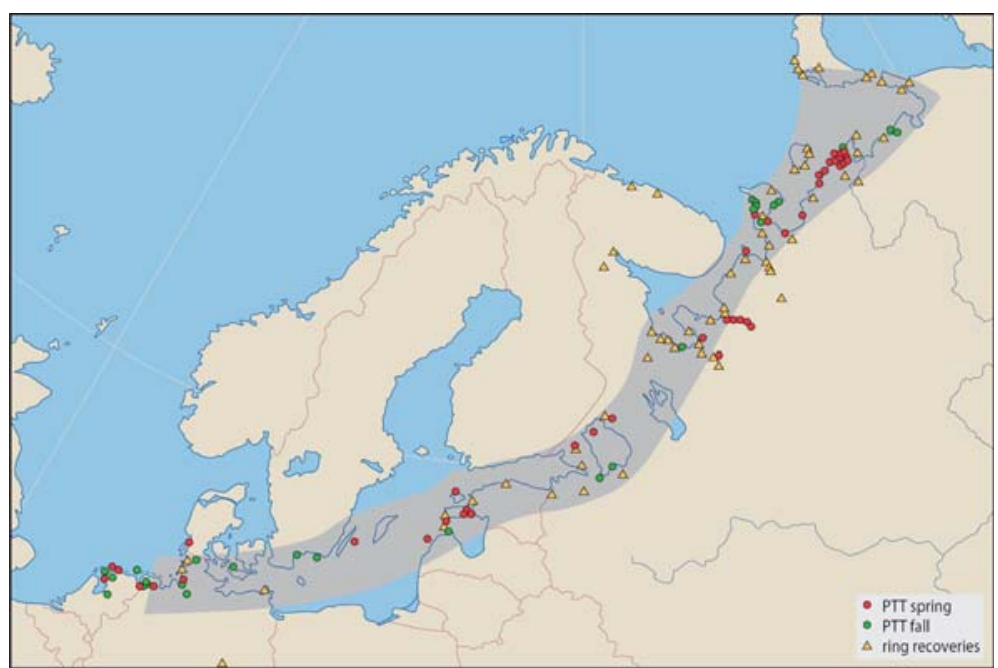

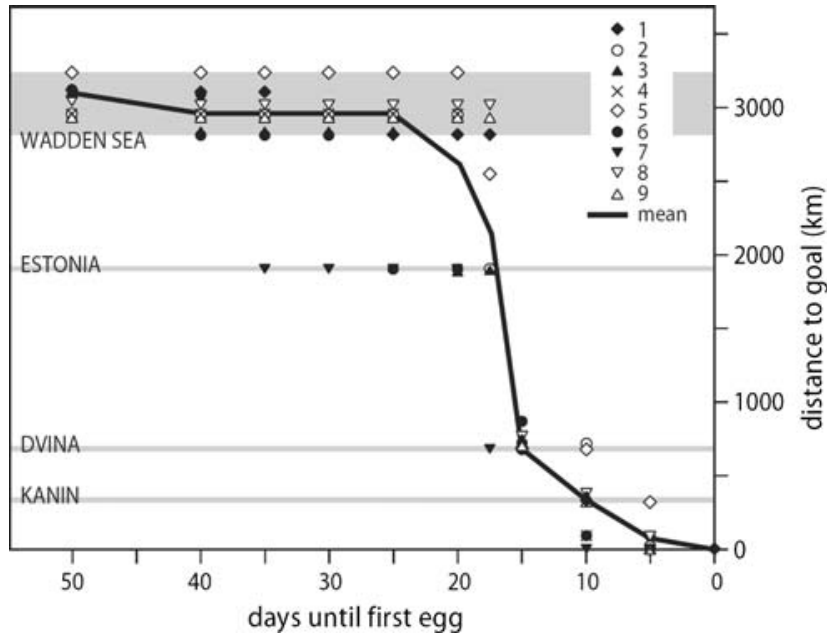

Fig. 4 Progress towards nesting colony (in $\mathrm{km}$ ) of nine satellitetagged Barnacle Geese in spring 2005, plotted relative to the day of laying the first egg. The Wadden Sea, Estonia, Dvina River and Kanin stopover sites identified in Fig. 3 are marked (adapted from Eichhorn 2005)

Clausen et al. (2003) presume laying occurred within 1 week of arrival. These findings point to a role for endogenous fat stores to support breeding, in keeping with data on carcass analysis of geese of the same species studied at a breeding station in Canada (Ankney 1984). Recent tracking studies on Pink-footed Geese Anser brachyrhynchus by Glahder et al. (2006) provide a detailed itinerary for individuals followed from Denmark via Arctic Norway to the breeding grounds on Spitsbergen. Although again lacking precise laying dates for the individuals tracked, the timing makes the conclusion inescapable that egg formation is already underway before the geese reach the Spitsbergen archipelago ('eggs made in Norway'; Glahder et al. 2006). Intensive observation of marked individuals during staging at a pre-breeding site on Spitsbergen showed an increase in abdominal profile despite the brief stop, indicating 'income feeding' supplementing the capital investment the geese brought from Norway.

Klaassen et al. (2006a) review a long-term data set for the Lesser Snow Goose A. c. caerulescens on the interval between arrival at the La Pérouse colony (Hudson Bay) and laying of the first egg. Analysis of stable isotopes in the egg components compared with local food sources and the maize exploited at stopovers on agricultural land were obtained from another dataset and allow a preliminary allocation to 'capital' or 'income' breeding. On this basis, income breeding prevailed in 5 seasons (typified by long delays on the breeding grounds before laying), whereas capital breeding was implicated in 11 seasons, with 2 seasons qualifying as border-line cases. Clearly the Lesser Snows are opportunistic in their reliance on 'imported nutrients' and follow a flexible strategy depending on local circumstances. We will consider the degree to which Greater Snow Geese A. caerulescens atlanticus depend on fat from body stores for laying and incubation in the following section.

A preliminary fat budget for spring migration and breeding in the Barnacle Goose

Eichhorn and co-workers (Eichhorn 2005; Eichhorn et al. 2006) have studied the dynamics of body stores in Barnacle Geese from birds captured or shot before departure from the Wadden Sea, at staging sites in Arctic Russia, and upon arrival at the nesting colony. We will present this here in the form of a fat budget, as lipids provide the lion's share of the energy budget (92\%) and this can be compared to breeding costs, again in terms of fat. At some sites, maximal fattening rates were established following the methods of Prop and Deerenberg (1991). Reconstruction of body 
mass changes during migration hinges on converting flight hours (from the satellite transmitters) to the energetic equivalent of $1 \mathrm{~h}$ of flight $=$ expenditure of $7 \mathrm{~g}$ fat from the empirical physiological studies of flight in this species undertaken by Butler and his team (Butler et al. 1998, 2000, 2003). The predicted changes in the fat stores in the female Barnacle Goose are displayed in Fig. 5, together with a provisional budget for breeding. During incubation, it was possible to weigh birds on the nest, and obtain estimates of the fat stores in the body from isotope dilution studies and hence derive a measure of fat utilisation (G. Eichhorn, in preparation). It will be noted that at hatch only a modest residue of fat is still in the body. Incubation requires a contribution far in excess of that needed to form the eggs and develop the oviduct. Requirements for clutch were estimated as in Drent et al. (2003) and oviduct costs from Vézina and Williams (2003, 2005). The fat stores originally laid down in the Wadden Sea suffice to pay for the 2,225 km migration to the first major stopover sites in the White Sea (Dvina region) and still leave a sizeable margin. By the time the birds reach the breeding colony further flight costs have been incurred for the additional $1,000 \mathrm{~km}$ (here booked as one flight for simplification), but additional fat stores have also been laid down. Quantitatively, the original fat stores from the Wadden Sea may represent as much as $40 \%$ of the stores available to the breeding female when she starts her clutch. Geese observed directly after completion of a major flight generally drink

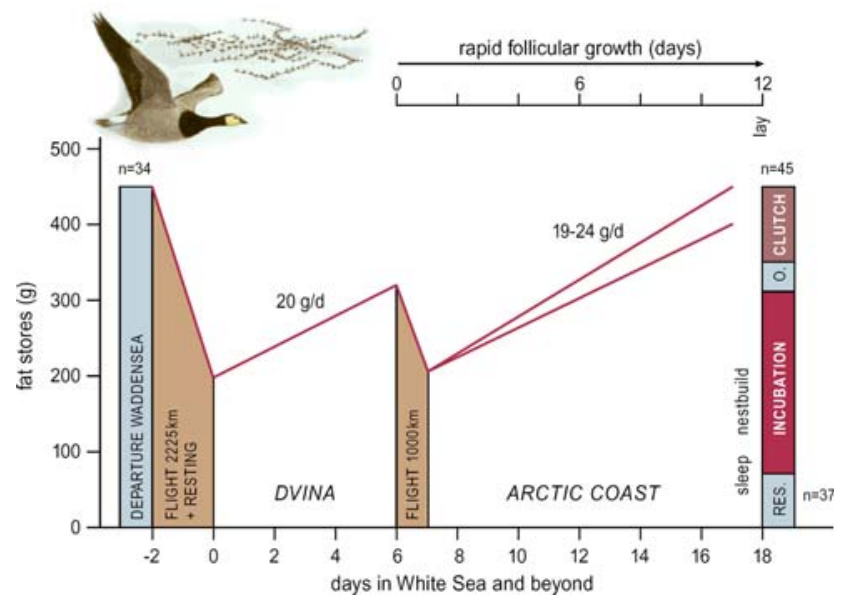

Fig. 5 Preliminary fat budget for spring migration and successful breeding in the Barnacle Goose following the flyway depicted in Fig. 3, and the timetable derived from ten satellite-tagged individuals in 2005. The fat stores at departure from the Wadden Sea $(n=34)$ and arrival at the nesting colony $(n=45)$ are derived from samples of captured and shot birds, respectively, and the dynamics of fat stores at the Dvina stopover are extrapolated values (see text). The fat budget for breeding allows for a modest residue at hatch $(n=37$ females sampled during incubation). A timetable for rapid follicular growth is shown above. Note that the mean date of arrival in the colony is 4-6 days before lay and sleep for extended periods before resuming feeding (as noted for other migrants; see Schwilch et al. 2002) and this 'lost time' is included in the first 2 days of the journey. Another loss of feeding time occurs just before commencing the clutch. Individuals we watched the last day before the first egg is laid spent much of the time resting rather than feeding, hence the interruption in accumulation of fat stores at that time in the figure.

Intensive observations of individual Greater Snow Geese supplemented by sampling of body stores from birds collected both in the colony and along the flyway (Gauthier et al. 1992, 2003; Choiniere and Gauthier 1995; Bêty et al. 2003, 2004) provide a reliable budget for comparison. Almost half (44\%) of the fat supplies accumulated by females during spring staging on the St Lawrence are depleted during the $3,000 \mathrm{~km}$ migration to the breeding area, Bylot Island (this compares to the decrement of $44 \%$ between Wadden Sea and White Sea in the Barnacle Goose). Judging from isotope signatures of body tissues of birds departing from the St Lawrence and arriving at Bylot, accumulation of additional body stores en route between these points is negligible. With respect to egg production, Greater Snows follow a mixed capital/income strategy where nutrients are obtained from food ingested on the breeding grounds as well as from the body stores. There is evidence that females draw on body fat to pay part of the metabolic cost of incubation, confirming the older findings of Ankney (in: Afton and Paulus 1992). Reproductive success peaks within a narrow time window, and contrary to expectation the earliest birds are not at an advantage. A relatively early arrival implies bridging a long gap before laying, with depletion of body stores not matched by local intake. The most successful individuals arrived about 3 days before the median, avoiding the poor prospects of both early and late birds.

Matching spring movements with plant growth: the Green Wave

The green wave hypothesis (Drent et al. 1978; Owen 1980) predicts that avian herbivores time their spring migration along the climatic gradient from temperate staging sites to their Arctic breeding grounds to match the spring flush of plant growth as it sprouts along their route. The geese thus surf along a wave of forage availability, 'riding the crest of the green wave' along their traditional flyway. Van der Graaf et al. (2006) have examined the match between vegetation and geese by meticulous study of forage growth at two staging sites and the final destination on the breeding station of a specific population of the Russian stock of the Barnacle Goose. Nutritive quality was measured as $\mathrm{N}$ content (as a proxy for protein content) of plant species 
exploited by the geese and expressed as $\mathrm{g} \mathrm{N}$ per square metre to include biomass (measured by clipping of aboveground material). At all three sites, this measure of potential forage shows a domed shape in relation to date (quadratic function) with the local peak displaced by approximately 100 days along the flyway from the Wadden Sea to the Arctic coast in Russia 3,500 km away. Geese departed from the Wadden Sea when the local forage was past its peak, and this pattern held for the Baltic staging site (Gotland) as well, strongly reminiscent of the findings of Prop et al. (2003) for the same species followed along the flyway from Scotland to Spitsbergen. Prop et al. (2003) documented migratory movements in relation to the timing of peaks in local food quality, and their results argue for an eviction of the birds as quality declines. The next stepping stone thus provides respite, because of the relative delay in spring growth. Van Eerden et al. (2005) collated migratory passage dates for Barnacle Geese of the Russian population, with dates of commencement of local grasses and sedges as deduced from the relationship with cumulative temperature thresholds established from agricultural research. Long-term temperature records from strategic weather stations along the route were employed for this calculation (five steps). Goose movements tracked vegetation development throughout the flyway, but, as in the direct measurements on plant quality and biomass undertaken by Van der Graaf et al. (2006), arrival on the breeding grounds was 'ahead of schedule'. Presumably arrival in the Arctic (with egg-laying commencing shortly thereafter) is timed to enable the newly-hatched goslings to profit from the local food peak. Van der Jeugd et al. (submitted) have indeed shown that laying dates in the colony in question match the survival prospects of the offspring (parents lay at the optimal time, neither too early or too late, with sharp cut-offs at each extreme). To recapitulate, the progression of geese along their spring flyway matches the timing of the nutritious early growth of their major food plants, but arrival on the breeding grounds is timed well in advance of the local peak supply in order to ensure survival of the offspring when they hatch (see Fig. 6).

McNaughton $(1979,1984)$ postulated an intimate mutual relationship between herbivores and their food supply, and suggested that migratory populations via their intensive grazing might elicit a short-term positive response by the target plants. This stimulation of aboveground growth would provide a bonus for the herbivores ('grazing optimisation'), particularly welcome because the ratio between fresh shoots and old growth would be enhanced. Not only might this influence the duration of exploitation of the new growth by the original consumer, but perhaps also facilitate utilisation by other species following in their footsteps. This issue has also been investigated in the Barnacle Goose (Van

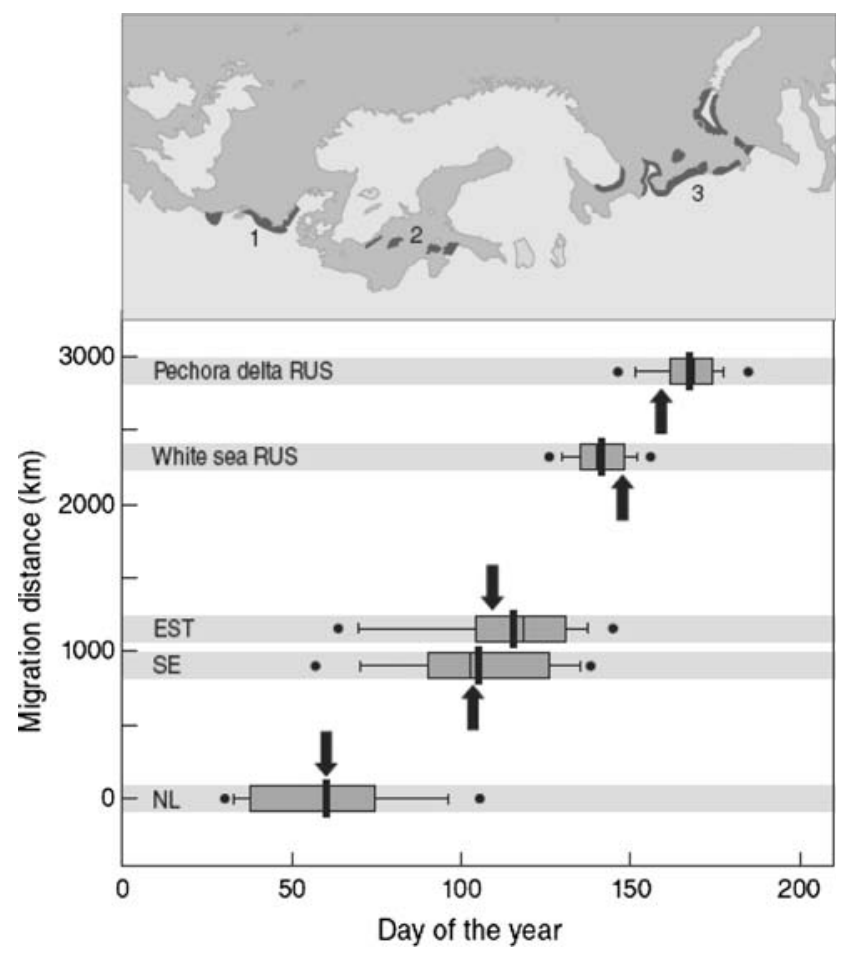

Fig. 6 Migratory timing of the Russian population of the Barnacle Goose (heavy arrows) in relation to commencement of spring growth of grasses along the flyway (box diagrams enclose central $75 \%$, the dots delimit $5 \%$ and $95 \%$ of predictions from 20 year data set, median $=$ thin crossbar, mean $=$ heavy crossbar . . Adapted from Van Eerden et al. 2005; observation sites indicated in map, $1=$ Netherlands NL, 2 = Swedsen SE and Estonia EST, 3 = Pechora delta

der Graaf et al. 2005; Stahl et al. 2006). Detailed measurements were undertaken on the vegetation (Festuca rubra swards on the saltmarsh) in conjunction with a regime of experimental grazing by captive geese in early spring designed to mimic the natural grazing pressure. Grazing significantly affected sward characteristics, reducing the proportion of dead biomass, and indeed culminated in an increase in potential harvest (in yield of $\mathrm{N}$ per square metre) for grazed as contrasted to ungrazed swards. At grazing pressures simulating the cumulative usage by wild geese ( 15 grazing minutes per square metre), these facilitative effects increased the carrying capacity of the site (yield to grazers) by about $20 \%$ compared to lower intensities. Increasing grazing pressures above the values that match usage by the wild flocks, however, did not lead to further increments: the unrestrained birds had already achieved an optimal grazing pressure. These advantages can only be reaped in areas free of human disturbance, where the geese can impose their grazing pressure without restraint (Bos and Stahl 2003). Taking the second facet of McNaughton's idea, there is some evidence that the wild herbivores at this spring staging site can profit from each other as the waves of two migrant goose species interact with the resident hares (Stahl et al. 
2006). So far there is no evidence for a growth-stimulation due to grazing in temperate salt marshes, but overwhelming evidence that grazing by geese enhances the quality of the food on offer. In the sub-Arctic salt marshes of the Hudson Bay lowlands Hik and Jefferies (1990) demonstrated that intensive goose grazing (by Lesser Snow Geese, A. c. caerulescens) enhanced productivity of their target food plants Puccinellia phryganodes and Carex subspathacea. In this nitrogen-limited system the increase of above-ground biomass depended entirely on nutrient inputs leaching from the goose droppings (acceleration of $\mathrm{N}$ cycle).

\section{Discussion}

Our conclusion that Arctic waterfowl (at least above a lean body mass of $1 \mathrm{~kg}$ ) must of necessity supplement local foraging by drawing on body stores for egg formation and incubation is in agreement with the analysis of Nolet (2006). Nolet modelled the dependence on body stores for breeding in relation to the energetics of migratory travel, under the constraint of reaching the goal in time to lay eggs at realistic dates. He found that all six species of Arctic waterfowl where speed of migratory travel had been measured empirically by tracking (ranging from Pintail $A$. acuta on through Arctic-nesting swans) must depend to some degree on body stores for successful reproduction. Recently, a massive tracking exercise on Pintail $(n=130)$ revealed that individuals breeding in subarctic Alaska on the tundra of the Yukon Delta originated from wintering quarters of the central valley of California. Virtually all intercalated a 2-month spring staging period in the Oregon-California border region, and the early nesters took a 'direct' route onwards to the Yukon $(3,250 \mathrm{~km})$ without extensive stop-over (Miller et al. 2005). Esler and Grand (1994) had previously shown that Pintails nesting in this region showed a heavy reliance on lipid stores in the body early in the season (large 'endogenous reserves' being needed for the clutch as well as for maintenance). Mann and Sedinger (1993) in another Alaskan study confirmed that lipid stores were drawn upon for both egg formation and maintenance. The tracking data make it likely that these critical fat stores are in fact 'flown in' from the spring feeding sites more than $3,000 \mathrm{~km}$ away.

Newton (2006) and Drent et al. (2006) have collated the evidence collected to date on the positive association of body weight at migration time and subsequent breeding success (mainly in waterfowl). It is our thesis that the causal link behind this association is the absolute necessity to arrive on the breeding grounds with adequate body stores. Arzel et al. (2006) have provided a massive compilation and point out that information on ducks (19 species tabulated) is often inadequate to decide whether endogenous or exogenous sources are relied on, in contrast to the dominant pattern of an endogenous contribution in geese and swans. In contrast to geese, ducks are more amenable to long-term feeding experiments in captivity and the results reported by Barboza and Jorde (2002) for A. rubripes would repay following up to quantify the endogenous component in egg production and incubation. Gunnarsson et al. (2006) provide evidence on the migratory timing of individual Blacktailed Godwits (Limosa limosa lapponica) wintering in Europe and breeding in Iceland that links the quality of the wintering site (judged by prey intake rates and survival) with the quality of the breeding stations (traditional sites conferring enhanced success). Marked individuals utilising the 'high quality' wintering sites (presumably achieving superior body condition) arrive earlier in Iceland and settle in the best breeding habitat. Such complex 'carry-over' effects from wintering or staging sites to the breeding area will doubtless prove the rule, with competition sorting the individuals at each stage.

These findings do not imply that all birds nesting in Arctic regions carry sufficient body stores with them to form the eggs. Especially for passerine migrants breeding at high latitudes, the role of endogenous reserves brought into the breeding grounds is still debated, and evidence based on individual migration itineraries is extremely difficult to obtain and therefore very scarce (Benson and Winker 2005; Smith and Moore 2003). However, given the stringent nesting schedules in arctic environments we would be greatly surprised if any waterfowl or shorebird species can complete incubation without drawing on body stores. Results from analysis of stable isotopes argue against a role of endogenous nutrients in egg formation of several shorebird species in the Arctic (Klaassen et al. 2001). Given the staggering costs of incubation in this group (Piersma et al. 2003) a subsidy from body stores is inescapable during this phase (note that females are the sole incubators in many shorebirds). Direct assessment of the provenance of body stores (especially fat) in incubating shorebirds by means of stable isotopes is an exciting avenue to follow up. We would argue that shorebirds may not be 'capital layers' but (when including egg care) must be considered 'capital breeders'. Morrison (2006) adduces indirect evidence for the Red Knot Calidris canutus in support of this contention. The validity of the premise that management of the state of body stores is a closely-run affair for the incubating female can be demonstrated directly for waterfowl. In a three-season study on the Wood Duck Aix sponsa Hepp et al. (1990) found that in the year of steepest mass loss during incubation, females heavy at hatch returned at higher rates to nest the next year than females light at that time. In the Common Eider, a species that as noted does not feed at all during incubation, Hanssen et al. (2004) and Hanssen (2006) working in 
Arctic Norway have revealed the narrow margins that apply to mass loss if the female is to complete brood care and return to breed the next season. By experimentally inducing an immune challenge (injection of non-pathogenic antigen, i.e. sheep red blood cells) in incubating hens 5 days after completing their clutch, daily mass loss increased compared to a control group (injected with sterile saline). Over an 8-day interval the 'challenged' birds had lost $225 \mathrm{~g}$ body mass (initial mass $1,910 \mathrm{~g}$ ) compared to a $195 \mathrm{~g}$ loss in the controls (initially $1,980 \mathrm{~g}$ ) and time to hatch was 0.6 days longer. Remarkably, in the 'challenged' birds the tendency to tend the brood that year was increased, but their return rate the next season was only half that of the controls. Admittedly, this is a complex experiment, but it can be argued that from the viewpoint of body condition even a modest degradation (heightened mass loss) during incubation equates with far-reaching fitness repercussions. Apparently, during their long fast incubating waterfowl are highly susceptible to upsets in the immune system (Hanssen et al. 2004).

If as we argue waterfowl and shorebirds follow the strategy to arrive in the breeding areas with body stores critical to see them through incubation, this will influence their migratory policy. Alerstam (2006) expands on this consideration and emphasises that the crucial issue is the ability to exploit final stop-over sites providing deposition rates of body stores in excess of what can be attained at the breeding destination. For the calculation the gain at the stop-over must be discounted for the costs of the flight still to be undertaken (see also Nolet and Klaassen 2005).

The tracking results for Arctic geese reviewed here support the contention that egg formation commences well before the birds reach the nesting colonies. In cases where the female has already entered the Arctic regions we are faced with the need to define 'endogenous' and 'exogenous' sources more precisely. For simplicity we here advocate reckoning the immediate vicinity of the nesting site (localities that can be reached in minutes rather than hours of flight) as belonging to the 'breeding grounds'. In contrast, directed flight from stop-over sites at distances of $50 \mathrm{~km}$ or more would qualify as part of the migratory journey, and nutrients garnered at that distance would strictly speaking be 'endogenous'.

According to the 'Green Wave hypothesis' spring movements track the onset of spring growth along the flyway. Our examination of this concept provides support for the notion along the route, and points to a narrow window of opportunity at each site. Late birds face depleted resources (Nolet and Drent 1998) and a decline in nutritive quality (Prop et al. 2003; Prop 2004) and will be penalised. The geese arrive on the breeding grounds well in advance of the local growth spurt, and it appears that egg-laying is timed to ensure that the goslings can exploit this resource. In this view, the use of body stores by the adults early in the season, before they can satisfy their requirements locally, is an adaptation to allow matching hatch dates to the optimal seasonal window. Similarly, the fattening rates of Pinkfooted Geese (inferred from changes in the abdominal profile of marked individuals) are much lower upon arrival on the breeding grounds (Spitsbergen) than at stop-over sites along the Norwegian coast exploited after departure from Denmark in early April (Klaassen et al. 2006b). Klaassen and co-workers (Tombre et al. 2005; Klaassen et al. 2006b) have modelled progression of the Pinkfeet along the spring flyway using dynamic programming and taking account of how intake rates are impacted by human disturbance at the stopover sites. In general terms the geese adhered to the predictions of the Green Wave, but the scaring campaigns resulted in redistribution of the Pinkfeet along the flyway, and impinged negatively on breeding success. Similarly, human disturbance at the spring staging sites of the Greater Snow Geese along the St Lawrence estuary in Canada has deleterious effects on breeding at their high Arctic nesting grounds 3,000 km away (Béchet et al. 2004).

Although geese with the advantage of their cultural traditions in migratory habits have provided numerous examples of flexibility in response to environmental change in the past (Sutherland 1998), the question arises whether they will be able to cope with the increased tempo of change expected in the near future (Stervander et al. 2005). Climate change models (IPCC 2001) call attention to the discontinuities in regions spanned by avian migrants in their annual cycle. There is already compelling evidence that conflicting trends affecting climate in winter, at the spring stopovers and on the breeding grounds in the insectivorous Pied Flycatcher Ficedula hypoleuca have disrupted the match between food supply and spring arrival (Both et al. 2006). Breeding is no longer within the optimal time span in favoured habitats in temperate Europe, and there is evidence for population declines resulting from a fall in reproductive output. Møller et al. (2004) have recently reviewed the topic of 'Birds and climate change' and we will merely touch here on events that potentially can disrupt the NE Atlantic flyway. We have shown that the Russian population of the Barnacle Goose proceeds along the climatic gradient in spring, timing its stopovers strategically to coincide with the local flush in nutritious spring growth. By employing cloche-type miniature greenhouses in the Wadden Sea, Baltic and at the breeding colony on the Barents Sea, Van der Graaf and co-workers (Van der Graaf 2006) simulated the effects of an elevation of $1^{\circ} \mathrm{C}$ on spring growth in the forage plants on which the geese depend. These data provide inputs to model the impact of climate change on the timing of spring growth and point to a weaker response in the Arctic. A temperature rise of $1^{\circ} \mathrm{C}$ (prediction of the IPCC 2001 for the period until 2050) would advance 
plant growth in the Wadden Sea and Baltic by 8 days, but at the Russian breeding site by only 4 days due to the strong impact of freezing temperatures well into May. This discrepancy is aggravated by the uncoupling of climate change documented by the regional model of Høgda et al. (2001), with continuing warming of the Baltic region but no change or even regression in the Arctic regions adjacent to our study area (Fig. 7). Indeed, weather records collected at Naryan Mar (close to our goose colony) over the past 35 years fail to reveal a warming trend, in contrast to increases at stations in the Baltic and Wadden Sea (Van der Graaf 2006). If the geese respond to the earlier 'spring bite' along the flyway they would thus arrive on the breeding grounds with a lengthened delay until local plant growth starts. The ability of the Barnacle Goose to cope with these desynchronised patterns of spring growth will thus depend heavily on exploiting staging opportunities in the White Sea, especially coastal wetlands where local animal husbandry has traditionally maintained swards attractive to geese. A complicating factor is the decline in this smallscale animal husbandry in the region, reducing the extent of hayfields and riverine meadows managed for cattle. Parallel changes have been documented in coastal communities in Estonia in recent decades (E. Puurmann in Hallanaro and Pylvänäinen 2002) leading to a loss of goose habitat for spring feeding (A. Leito, personal communication). These complexities warn against assuming that these migrant

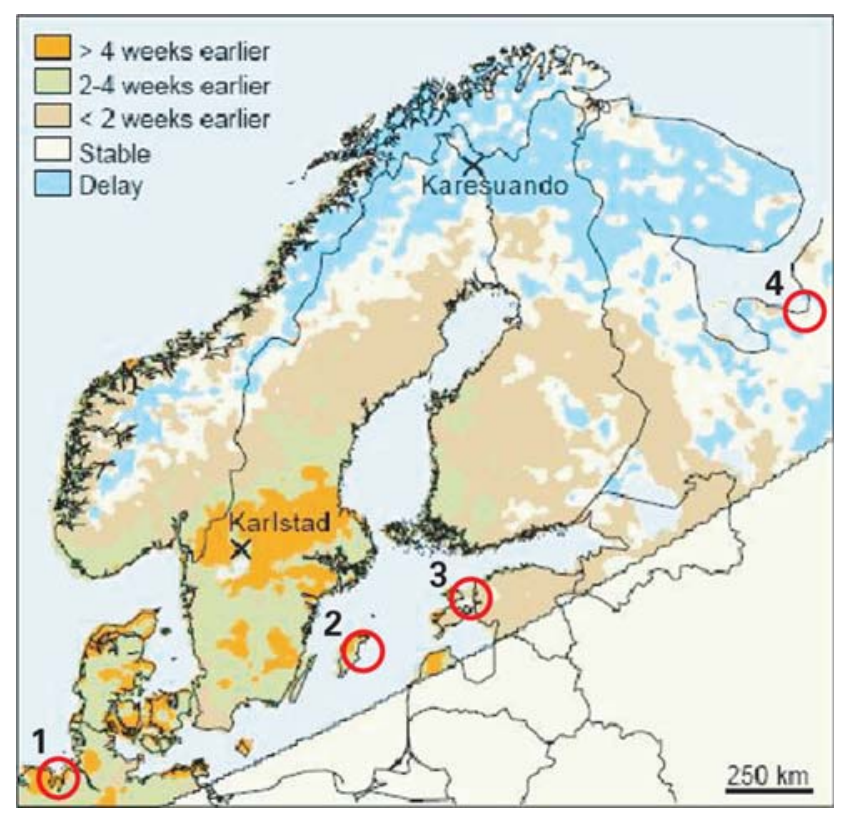

Fig. 7 Change in onset of spring (see colour key) 1981-1998 along the migratory route of the Barnacle Goose en route from the Wadden Sea (1) via Gotland, Sweden (2) and coastal Estonia (3) to the Dvina delta (4) in the White Sea, a vital stopover before reaching the breeding colonies on the Arctic coast (not shown). Onset of spring plant growth for the 17-year period was derived from NDVI values (resolution $8 \mathrm{~km}$ ). Modified from Høgda et al. (2001) birds will always be able to cope successfully with a mismatch in rates of environmental change at various points of their annual trajectory.

Climate change goes hand in hand with change in land use as agricultural developments ebb and flow, and virtually all goose populations now face a 'squeeze' where the patches of natural habitat providing forage become increasingly restricted. The ability to shift to habitats dominated by agricultural crops differs between the species and season, and recent reviews stress the uncertainties associated with ongoing change (Abraham et al. 2005; Gauthier et al. 2005; Ward et al. 2005; Fox et al. 2005; Van Eerden et al. 2005). Jefferies et al. (2006) point out that current agricultural policy in both North America and Europe will tend to reduce the acreage and quality of crop foods available to geese in winter (and, in many populations, spring as well, see, e.g., Percival and Percival 1997). Taking a broader view to include all waterfowl, Long et al. (2007) point out that in Central and South America, Africa and Asia, in fact the majority of populations are now in decline, driven by loss of wetland habitat (climate and man conspiring) and a variety of anthropogenic factors. The complacency we might feel from the perspective of Europe and North America where decreases are in the minority is thus misplaced.

Acknowledgements We thank the contributors to the 2004 Workshop Travelling to Breed of the European Science Foundation for sharing their findings with us [available in Ardea 94(3), 2006]. Our fieldwork was supported by the European Science Foundation (BIRD Programme Optimal Migration in Birds), the Netherlands Organisation for Scientific Research (Netherlands Arctic Programme), the Schure-Beijerinck-Popping Fonds of the Royal Netherlands Academy of Sciences, and Groningen University. G.E. was financially supported by scholarships from the 'Marianne und Dr Fritz WalterFischer Stiftung', Germany, and the 'Ubbo Emmius Programme' at the University of Groningen. J.S. acknowledges financial support from the 'Deutsche Forschungsgemeinschaft'.

\section{References}

Abraham KF, Jefferies RL, Alisauskas RT (2005) The dynamics of landscape change and snow geese in mid-continent North America. Global Change Biol 11:841-855

Afton AD, Paulus SL (1992) Incubation and brood care. In: Batt BDJ, Afton AD, Anderson MG, Ankney CD, Johnson DH, Kadlec JA, Krapu GL (eds) Ecology and management of breeding waterfowl. University of Minnesota Press, Minneapolis, pp 62-108

Alerstam T (2006) Strategies for the transition to breeding in timeselected bird migration. Ardea 94:347-357

Alerstam T, Hjort C, Högsted G, Jönsson PE, Karlsson J, Larsson B (1986) Spring migration of birds across the Greenland Inlandice. Meddelelser om Grønland, Bioscience 21:1-38

Alisauskas RT, Ankney CD (1992) Egg laying and nutrient reserves. In: Batt BDJ, Afton AD, Anderson MG, Ankney CD, Johnson DH, Kadlec JA, Krapu GL (eds) Ecology and management of breeding waterfowl. University of Minnesota Press, Minneapolis, pp 30-61 
Ankney CD (1984) Nutrient reserve dynamics of breeding and molting Brant. Auk 101:361-370

Arzel C, Elmberg J, Guillemain M (2006) Ecology of springmigrating Anatidae: a review. J Ornithol 147:167-184

Barboza PS, Jorde DG (2002) Intermittent fasting during winter and spring affects body composition and reproduction of a migratory duck. J Comp Physiol B, Biochem Syst Environ Physiol 172:419-434

Béchet A, Giroux JF, Gauthier G (2004) The effects of disturbance on behaviour, habitat use and energy of spring staging snow geese. J Appl Ecol 41:689-700

Benson AM, Winker K (2005) Fat-deposition strategies among highlatitude passerine migrants. Auk 122:544-557

Bêty J, Gauthier G, Giroux JF (2003) Body condition, migration, and timing of reproduction in snow geese: a test of the conditiondependent model of optimal clutch size. Am Nat 162:110-121

Bêty J, Giroux JF, Gauthier G (2004) Individual variation in timing of migration: causes and reproductive consequences in greater snow geese (Anser caerulescens atlanticus). Behav Ecol Sociobiol 57:1-8

Boismenu C, Gauthier G, Larochelle J (1992) Physiology of prolonged fasting in Greater Snow Geese (Chen caerulescens atlantica). Auk 109:511-521

Bos D, Stahl J (2003) Creating new foraging opportunities for darkbellied brent Branta bernicla and barnacle geese Branta leucopsis in spring: insights from a large-scale experiment. Ardea 91:153-165

Both C, Bouwhuis S, Lessells CM, Visser ME (2006) Climate change and population declines in a long-distance migratory bird. Nature 441:81-83

Bowler J (2005) Breeding strategies and biology. In: Kear J (ed) Ducks, geese and swans, vol.1. Oxford University Press, Oxford, pp 68-111

Butler PJ, Woakes AJ, Bishop CM (1998) Behaviour and physiology of Svalbard Barnacle Geese Branta leucopsis during their autumn migration. J Avian Biol 29:536-545

Butler PJ, Woakes AJ, Bevan RM, Stephenson R (2000) Heart rate and rate of oxygen consumption during flight of the barnacle goose, Branta leucopsis. Comp Biochem Physiol Part A Mol Integr Physiol 126:379-385

Butler PJ, Bishop CM, Woakes AJ (2003) Chasing a wild goose: posthatch growth of locomotor muscles and behavioural physiology of migration of an Arctic goose. In: Berthold P, Gwinner E, Sonnenschein E (eds) Avian migration. Springer, Berlin Heidelberg, New York, pp 527-542

Carey C (1996) Female reproductive energetics. In: Carey C (ed) Avian energetics and nutritional ecology. Chapman \& Hall, New York, pp 324-374

Choiniere L, Gauthier G (1995) Energetics of reproduction in female and male Greater Snow Geese. Oecologia 103:379-389

Clausen P, Green M, Alerstam T (2003) Energy limitations for spring migration and breeding: the case of brent geese Branta bernicla tracked by satellite telemetry to Svalbard and Greenland. Oikos 103:426-445

Drent RH, Daan S (1980) The prudent parent-energetic adjustments in avian breeding. Ardea 68:225-252

Drent R, Weijand B, Ebbinge B (1978) Balancing the energy budget of arctic breeding geese throughout the annual cycle: a progress report. Verh Ornithol Ges Bayern 23:239-264

Drent R, Both C, Green M, Madsen J, Piersma T (2003) Pay-offs and penalties of competing migratory schedules. Oikos 103:274-292

Drent RH, Fox AD, Stahl J (2006) Travelling to breed. J Ornithol 147:122-134

Eichhorn G (2005) Northward bound: fat for flight. How Barnacle Geese budget their spring travels. In: Drent RH, Tinbergen JM,
Bakker JP, Piersma T (eds) Seeking nature's limits. KNNV, Utrecht, pp 102-113

Eichhorn G, Afanasyev V, Drent RH, Van der Jeugd HP (2006) Spring stopover routines in Russian Barnacle Geese Branta leucopsis tracked by resightings and geolocation. Ardea 94:667678

Esler D, Grand JB (1994) The role of nutrient reserves for clutch formation by Northern Pintails in Alaska. Condor 96:422-432

Fox AD, Glahder CM, Walsh AJ (2003) Spring migration routes and timing of Greenland white-fronted geese-results from satellite telemetry. Oikos 103:415-425

Fox AD, Madsen J, Boyd H, Kuijken E, Norriss DW, Tombre IM, Stroud DA (2005) Effects of agricultural change on abundance, fitness components and distribution of two arctic-nesting goose populations. Global Change Biol 11:881-893

Gabrielsen GW, Mehlum F, Karlsen HE, Andresen O, Parker E (1991) Energy cost during incubation and thermoregulation in the female Common Eider Somateria mollissima. Norsk Polarinst Skr 195:51-62

Garrettson PR, Rohwer FC (1998) Reproductive effort and survival of wild Blue-winged Teal Anas discors with backpack harness and implant transmitters. Can Field Nat 112:212-216

Garrettson PR, Rohwer FC, Moser EB (2000) Effects of backpack and implanted radiotransmitters on captive Blue-winged Teal. J Wildl Manage 64:216-222

Gauthier G, Giroux JF, Bedard J (1992) Dynamics of fat and protein reserves during winter and spring migration in Greater Snow Geese. Can J Zool 70:2077-2087

Gauthier G, Bêty J, Hobson KA (2003) Are greater snow geese capital breeders? New evidence from a stable-isotope model. Ecology $84: 3250-3264$

Gauthier G, Giroux JF, Reed A, Béchet A, Belanger L (2005) Interactions between land use, habitat use, and population increase in greater snow geese: what are the consequences for natural wetlands? Global Change Biol 11:856-868

Glahder CM, Fox AD, Hübner CE, Madsen J, Tombre IM (2006) Prenesting site use of satellite transmitter tagged Svalbard Pinkfooted Geese Anser brachyrhynchus. Ardea 94:679-690

Green M, Alerstam T, Clausen P, Drent R, Ebbinge BS (2002) Darkbellied Brent Geese Branta bernicla bernicla, as recorded by satellite telemetry, do not minimize flight distance during spring migration. Ibis 144:106-121

Groscolas R, Schreiber L, Morin F (1991) The use of tritiated water to determine protein and lipid utilization in fasting birds: a validation-study in incubating Great-winged petrels, Pterodroma macroptera. Phys Zool 64:1217-1233

Gunnarsson TG, Gill JA, Atkinson PW, Gelinaud G, Potts PM, Croger RE, Gudmundsson GA, Appleton GF, Sutherland WJ (2006) Population-scale drivers of individual arrival times in migratory birds. J Anim Ecol 75:1119-1127

Hallanaro E-L, Pylvänäinen M (2002) Nature in Northern Europebiodiversity in a changing environment. Nord 2001:13, Nordic Council of Ministers, Copenhagen

Hanssen SA (2006) Costs of an immune challenge and terminal investment in a long-lived bird. Ecology 87:2440-2446

Hanssen SA, Hasselquist D, Folstad I, Erikstad KE (2004) Costs of immunity: immune responsiveness reduces survival in a vertebrate. Proc R Soc Lond B 271:925-930

Hepp GR, Kennamer RA, Harvey WF (1990) Incubation as a reproductive cost in female Wood Ducks. Auk 107:756-764

Hik DS, Jefferies RL (1990) Increases in the net aboveground primary production of a salt marsh forage grass: a test of the predictions of the herbivore-optimization model. J Ecol 78:180-195

Hobson KA (2003) Making migratory connections with stable isotopes. In: Berthold P, Gwinner E, Sonnenschein E (eds) 
Avian migration. Springer, Berlin Heidelberg New York, pp 379-391

Hobson KA (2006) Using stable isotopes to quantitatively track endogenous and exogenous nutrient allocations to eggs of birds that travel to breed. Ardea 94:359-369

Høgda KA, Karlsen SR, Solheim I (2001) Climate change impact on growing season in Fennoscandia studied by a time series of NOAA AVHRR NDVI data. Proceedings of IGARSS 2001, Sydney

Houston AI, Stephens PA, Boyd IL, Harding KC, McNamara JM (2007) Capital or income breeding? A theoretical model of female reproductive strategies. Behav Ecol 18:241-250

Hübner CE (2006) The importance of pre-breeding areas for the arctic Barnacle Goose Branta leucopsis. Ardea 94:701-713

Hupp JW, Ruhl GA, Pearce JM, Mulcahy DM, Tomeo MA (2003) Effects of implanted radio transmitters with percutaneous antennas on the behavior of Canada Geese. J Field Ornithol $74: 250-256$

Hupp JW, Pearce JM, Mulcahy DM, Miller DA (2006a) Effects of abdominally implanted radiotransmitters with percutaneous antennas on migration, reproduction, and survival of Canada geese. J Wildl Manage 70:812-822

Hupp JW, Schmutz JA, Ely CR (2006b) The prelaying interval of Emperor Geese on the Yukon-Kuskokwim Delta, Alaska. Condor 108:912-924

IPCC (2001) Climate change 2001: synthesis report. Cambridge University Press, Cambridge

Jefferies RL, Drent RH, Bakker JP (2006) Connecting Arctic and temperate wetlands and agricultural landscapes: the dynamics of goose populations in response to global change. In: Verhoeven JTA, Beltman B, Bobbink R, Whigham DF (eds) Wetlands and natural resource management. Ecological studies, vol 190. Springer, Berlin Heidelberg New York, pp 293-314

Klaassen M (2003) Relationships between migration and breeding strategies in arctic breeding birds. In: Berthold P, Gwinner E, Sonnenschein E (eds) Avian migration. Springer, Berlin Heidelberg New York, pp 237-249

Klaassen M, Lindström A, Meltofte H, Piersma T (2001) Arctic waders are not capital breeders. Nature 413:794

Klaassen M, Abraham KF, Jefferies RL, Vriska M (2006a) Factors affecting the site of investment, and the reliance on savings for arctic breeders: the capital-income dichotomy revisited. Ardea 94:371-384

Klaassen M, Bauer S, Madsen J, Ingunn T (2006b) Modelling behavioural and fitness consequences of disturbance for geese along their spring flyway. J Appl Ecol 43:92-100

Krechmar AV, Kondratyev AV (2006) Waterfowl birds of North-East Asia. Academic Science, Far East Branch, Magadan

Le Maho Y, Vu Van Kha H, Koubi H, Dewasmes G, Girard J, Ferre P, Cagnard M (1981) Body composition, energy expenditure, and plasma metabolites in long-term fasting geese. Am J Physiol 241:E342-E354

Lepage D, Gauthier G, Reed A (1998) Seasonal variation in growth of greater snow goose goslings: the role of food supply. Oecologia 114:226-235

Lindström $\AA$ (2003) Fuel deposition rates in migrating birds: causes, constraints and consequences. In: Berthold $\mathrm{P}$, Gwinner $\mathrm{E}$, Sonnenschein E (eds) Avian migration. Springer, Berlin Heidelberg New York, pp 307-320

Long PR, Székely T, Kershaw M, O’Connell M (2007) Ecological factors and human threats both drive wildfowl population declines. Anim Conserv 10:183-191

Madsen J, Klaassen M (2006) Assessing body condition and energy budget components by scoring abdominal profiles in freeranging pink-footed geese Anser brachyrhynchus. J Avian Biol $37: 283-287$
Mann FE, Sedinger JS (1993) Nutrient-reserve dynamics and control of clutch size in Northern Pintails breeding in Alaska. Auk 110:264-278

McNaughton SJ (1979) Grazing as an optimization process: grassungulate relationships in the Serengeti. Am Nat 113:691-703

McNaughton SJ (1984) Grazing lawns: animals in herds, plant form, and coevolution. Am Nat 124:863-886

Meijer T, Drent R (1999) Re-examination of the capital and income dichotomy in breeding birds. Ibis 141:399-414

Miller MR, Eadie JM (2006) The allometric relationship between resting metabolic rate and body mass in wild waterfowl (Anatidae) and an application to estimation of winter habitat requirements. Condor 108:166-177

Miller MR, Takekawa JY, Fleskes JP, Orthmeyer DL, Casazza ML, Perry WM (2005) Spring migration of Northern Pintails from California's Central Valley wintering area tracked with satellite telemetry: routes, timing, and destinations. Can J Zool 83:13141332

Møller AP, Fiedler W, Berthold P (eds) (2004) Birds and climate change. Adv Ecol Res 35:1-251

Morrison RIG (2006) Body transformations, condition and survival in the Red Knots Calidris canutus travelling to breed at Alert, Ellesmere Island, Canada. Ardea 94:607-618

Newton I (2006) Can conditions experienced during migration limit the population levels of birds? J Ornithol 147:146-166

Nolet BA (2006) Speed of spring migration of Tundra Swans Cygnus columbianus in accordance with income or capital breeding strategy? Ardea 94:579-591

Nolet BA, Drent RH (1998) Bewick's Swans refuelling on pondweed tubers in the Dvina Bay (White Sea) during their spring migration: first come, first served. J Avian Biol 29:574-581

Nolet BA, Klaassen M (2005) Time and energy constraints in demanding phases of the annual cycle: an example of time limitation in refuelling migratory swans. Oikos 111:302-310

Owen M (1980) Wild geese of the world: their life history and ecology. Batsford, London

Parker H, Holm H (1990) Patterns of nutrient and energy expenditure in female Common Eiders nesting in the High Arctic. Auk 107:660-668

Percival SM, Percival T (1997) Feeding ecology of barnacle geese on their spring staging grounds in northern Iceland. Ecography 20:461-465

Piersma T, Lindström Å, Drent RH, Tulp I, Jukema J, Morrison RIG, Reneerkens J, Schekkerman H, Visser GH (2003) High daily energy expenditure of incubating shorebirds on High Arctic tundra: a circumpolar study. Funct Ecol 17:356-362

Prop J (2004) Food finding — on the trail to successful reproduction in migratory geese. $\mathrm{PhD}$ Thesis, University Groningen, The Netherlands

Prop J, Deerenberg C (1991) Spring staging in Brent Geese Branta bernicla: feeding constraints and the impact of diet on the accumulation of body reserves. Oecologia 87:19-28

Prop J, Black JM, Shimmings P (2003) Travel schedules to the high arctic: barnacle geese trade-off the timing of migration with accumulation of fat deposits. Oikos 103:403-414

Reese E (2006) Bewick's Swan. Poyser, London

Schmutz JA, Hobson KA, Morse JA (2006) An isotopic assessment of protein from diet and endogenous stores: effects on egg production and incubation behaviour of geese. Ardea 94:385-397

Schwilch R, Piersma T, Holmgren NMA, Jenni L (2002) Do migratory birds need a nap after a long non-stop flight? Ardea 90:149-154

Sedinger JS, Flint PL (1991) Growth-rate is negatively correlated with hatch date in Black Brant. Ecology 72:496-502

Sedinger JS, Raveling DG (1986) Timing of nesting by Canada Geese in relation to the phenology and availability of their food plants. J Anim Ecol 55:1083-1102 
Smith RJ, Moore FR (2003) Arrival fat and reproductive performance in a long-distance passerine migrant. Oecologia 134:325-331

Spaans B, van der Veer W, Ebbinge BS (1999) Cost of incubation in a Greater White-fronted Goose. Waterbirds 22:151-155

Spaans B, van't Hoff CA, van der Veer W, Ebbinge BS (2007) The significance of female body stores for egg laying and incubation in dark-bellied Brent Geese Branta bernicla bernicla. Ardea 95:3-15

Speakman JR, Visser GH, Ward S, Krol E (2001) The isotope dilution method for the evaluation of body composition. In: Speakman JR (ed) Body composition analysis of animals: a handbook of nondestructive methods. Cambridge University Press, Cambridge, pp 56-98

Stahl J, Van der Graaf AJ, Drent RH, Bakker JP (2006) Subtle interplay of competition and facilitation among small herbivores in coastal grasslands. Funct Ecol 20:908-915

Stervander M, Lindström Å, Jonzén N, Andersson A (2005) Timing of spring migration in birds: long-term trends, North Atlantic Oscillation and the significance of different migration routes. J Avian Biol 36:210-221

Sutherland WJ (1998) Evidence for flexibility and constraint in migration systems. J Avian Biol 29:441-446

Takekawa JY, Kurechi M, Orthmeyer DL, Sabano Y, Uemura S, Perry WM, Yee JL (2000) A Pacific spring migration route and breeding range expansion for Greater White-fronted Geese wintering in Japan. Global Environ Res 4:155-168

Tombre IM, Madsen J, Tømmervik H, Haugen KP, Eythórsson E (2005) Influence of organised scaring on distribution and habitat choice of geese on pastures in Northern Norway. Agric Ecosys Environ 111:311-320

Van der Graaf AJ (2006) Geese on a green wave: flexible migrants in a changing world. PhD Thesis, University Groningen, The Netherlands

Van der Graaf AJ, Stahl J, Bakker JP (2005) Compensatory growth of Festuca rubra after grazing: can migratory herbivores increase their own harvest during staging? Funct Ecol 19:961-969

Van der Graaf AJ, Stahl J, Klimkowska A, Bakker JP, Drent RH (2006) Surfing on a green wave — how plant growth drives spring migration in the Barnacle Goose Branta leucopsis. Ardea 94:567-577

Van Eerden MR, Drent RH, Stahl J, Bakker JP (2005) Connecting seas: western Palaearctic continental flyway for water birds in the perspective of changing land use and climate. Global Change Biol 11:894-908

Vézina F, Williams TD (2003) Plasticity in body composition in breeding birds: what drives the metabolic costs of egg production? Physiol Biochem Zool 76:716-730

Vézina F, Williams TD (2005) Interaction between organ mass and citrate synthase activity as an indicator of tissue maximal oxidative capacity in breeding European Starlings: implications for metabolic rate and organ mass relationships. Funct Ecol 19:119-128

Ward DH, Reed A, Sedinger JS, Black JM, Derksen DV, Castelli PM (2005) North American Brant: effects of changes in habitat and climate on population dynamics. Global Change Biol 11: $869-880$ 